\title{
Composition of biologically active lipids of Lamiaceae seed oils
}

\author{
By M. D. Zlatanov and G. A. Antova \\ University of Plovdiv, Department of Chemical Technology, 24 Tzar Assen Str., 4000 Plovdiv, \\ Bulgaria, E-mail: magzlat@ pu.acad.bg
}

\section{RESUMEN}

Composición de lípidos biológicamente activos de aceites de semilla Lamiaceae.

Se estudia el contenido en aceite, fosfolípidos, esteroles y tocoferol de semillas pertenecientes a 7 especies de la Familia $\mathrm{La}$ miaceae. Se encontraron valores comprendidos entre $8.7-28.6 \%$ para los aceites en las semillas. El contenido en fosfolípidos para los aceites fue del $1.0-1.6 \%$. Los principales componentes de la fracción fosfolípido fueron: fosfatidilcolina (35.5-63.1\%), fosfatidilinositol (19.1-30.2\%) y fosfatidiletanolamina (5.8-21.6\%). En la fracción de esteroles $(0.1-0.3 \%$ de esteroles totales en las muestras de aceites), $64.8-86.3 \%$ estaban presentes en forma libre y $13.7-35.2 \%$ como esteres de esteroles. El $\beta$-Sitosterol es el que predomina $(48.8-87.9 \%)$, seguido de campesterol $(1.5-22.5 \%)$ y stigmasterol $(1.1-12.8 \%)$. Se encontró un contenido en tocoferoles de 6.3$649.7 \mathrm{mg} / \mathrm{kg}$, principalmente $\alpha$-tocopherol (48.5-99.9\%).

PALABRAS-CLAVE: Aceite de semilla -- Composición lipídica -Lamiaceae.

\section{SUMMARY}

Composition of biologically active lipids of lamiaceae seed oils.

The content of glyceride oil, phospholipid, sterol and tocopherol composition of 7 species of fam. Lamiaceae seeds were investigated. $8.7-28.6 \%$ of glyceride oil in the seeds were determined. The content of phospholipids in the oils was found to be $1.0-1.6 \%$. Phosphatidylcholine $(35.5-63.1 \%)$, phosphatidylinositol (19.1-30.2\%) and phosphatidylethanolamine (5.8-21.6\%) were the main components in the phospholipid fraction. In the sterol fraction $(0.1-0.3 \%$ total sterols in the oils) $64.8-86.3 \%$ are in free form and $13.7-35.2 \%$ as sterol esters. $\beta$-Sitosterol predominates in all glyceride oils $(48.8-87.9 \%)$, followed by campesterol $(1.5-22.5 \%)$ and stigmasterol (1.1-12.8\%). 6.3-649.7 mg/kg tocopherols were found, mainly $\alpha$-tocopherol (48.5-99.9\%).

KEY-WORDS: Lamiaceae -- Lipid composition -- Seed oil.

\section{INTRODUCTION}

Botanical family Lamiaceae (Labiatae) includes many species of plants, which are widespread in the temperate areas of the Northern terrestrial globe. A characteristic feature of the representatives of this family is that, besides the glyceride oils, the seeds contain essential oils with condiment (Pamukov D. and C. Ahtaradjiev, 1990) or pharmacological (Sokolov S. and J. Zamotaev, 1984; Weiss R, 1974,
Slavik B. and V. Choe, 1978) character. Some of them are cultivated and used as a source for obtaining honey, essential oils such as limonen, geraniol, menthol, citrol etc., for perfumery and cosmetics (Georgiev E., 1989). The seeds and leaves are used as food condiments in the production of beer, wine, liquors, for aromatization of sausages, meat, salads, cheese etc. (Stojanov and Kitanov, 1960). In the recent years investigations of the content and composition of the essential oils were carried out, but information about the composition of glyceride oil is scanty. It was not found information about content and composition of biological active substances such as phospholipids, sterols and tocopherols.

The data about the application of some representatives of family Lamiaceae in perfumery, confectionery and food industry directed our interest to some introduced but unstudied species. This work presents the results from comparative investigations of the content of glyceride oil in the seeds, sterol and tocopherol content and composition of phospholipid fraction of 7 species of Lamiaceae family which are:

1. Leonurus cardiaca $L$.

2. Marrubium vulgare $L$.

3. Mentha spicata $L$.

4. Nepeta cataria L.

5. Salvia aethopis $L$.

6. Salvia nutans $L$.

7. Salvia verticalata $L$.

\section{MATERIAL AND METHODS}

Fruit material. The investigated seeds were provided from the Plovdiv region in South Bulgaria. Botanical affiliation was established by routine methods (Gramatikov, 1992). The investigations were carried out on air dried seeds in technical ripeness.

Glyceride oil isolation. The oils were extracted in Soxhlet apparatus with fresh distilled n-hexane for $8 \mathrm{~h}$. After rotation vacuum distillation of the solvent the extracted oils were dried and weighed (Ivanov and Aitzetmüller, 1995).

Phospholipid composition. Lipids were extracted from the seeds by Folch procedure (Beshkov and Ivanova, 1972). Polar lipids were separated from unpolar lipids by column chromatography. The 
phospholipid constituents were separated by two directional thin - layer chromatography on Silica gel $60 \mathrm{G}$ "Merck", impregnated with $1 \%\left(\mathrm{NH}_{4}\right)_{2} \mathrm{SO}_{4}$ water solution (Beshkov and Ivanova, 1972). The first direction was carried out in chloroform : methanol: ammonia 65: 25: 5 $\mathrm{v} / \mathrm{v} / \mathrm{v}$ and second in chloroform: methanol: ammonia: acetic acid : water 50:20:10:10:5 v/v/v/v/v. The spots of the separated individual phospholipids were identified by spraying with specific reagents (Kates, 1972). In addition, $\mathrm{R}_{\mathrm{F}}$ and standard spots were used for definitive identification. The quantitative evaluation was carried out spectrophotometrically at $700 \mathrm{~nm}$ (Beshkov and Ivanova, 1972).

Sterol composition. The free sterols and sterol esters were separated from the other oil constituents by preparative TLC on Silica gel $60 \mathrm{G}$ "Merck" and mobile phase $n$-hexane : diethyl ether $1: 1$. The sterol esters were saponified with ethanolic $\mathrm{KOH}$, extracted and purified by TLC. The content and individual composition of sterols was carried out by gas chromatography using HP 5890 A unit with FID, 25 m $0.25 \mathrm{~mm}$ ID (internal diameter), $0.25 \mathrm{~m}$ Fused Silica film thickness capillar column impregnated with $3 \%$ OV-17 and conditions as follows:

column temperature programme -260 to $300^{\circ} \mathrm{C}$, at $6^{\circ} \mathrm{C} / \mathrm{min}$

detector temperature $320^{\circ} \mathrm{C}$, injector temperature $300^{\circ} \mathrm{C}$

gas carrier - nitrogen, $20 \mathrm{~cm}^{3} / \mathrm{min}$

Betulin was used as internal standard for quantitative evaluation of sterols (ISO 12228, 1999). Identification was confirmed by comparing the retention time of the individual constituents with that of standard solution containing cholesterol, campesterol, stigmasterol and sitosterol (Homberg and Bielefeld, 1989).
Tocopherol composition. Tocopherols and tocotrienols were analysed directly in the oils by HPLC with fluorescence detection (ISO, 1989, Ivanov and Aitzetmuller, 1995). "Merck-Hitachi" unit

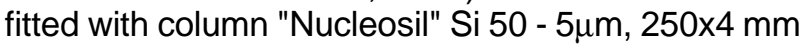
and fluorescent detector "Merck-Hitachi" F 1000 was used. The operating conditions were as follows: excitation wavelength set at $295 \mathrm{~nm}$, emission wavelength at $330 \mathrm{~nm}$, mobile phase $\mathrm{n}$-hexane : dioxane 94: 4 , rate of mobile phase $1 \mathrm{~cm}^{3} / \mathrm{min}$. The peaks were identified by using authentic individual tocopherol standards provided by "Merck".

\section{RESULTS AND DISCUSSION}

Data on the composition of the investigated plants are presented in Table I which shows that the seeds of Lamiacae family contain significant amounts of glyceride oil. Except for Nepeta cataria $L$. the investigated seeds of Lamiacae family contain more than $20.0 \%$ of glyceride oil. The oils also have a high content of phospholipids (1.0- $1.6 \%$ ). These values are closed to date about other wild plants (Ivanov and Aitzetmüller, 1995).

The amount of sterols and tocopherols in the oils of this family was lower then other plants used as condiments $0.1-0.3 \%$ and $14.7-649.7 \mathrm{mg} / \mathrm{kg}$ respectively, as compared with $0.2-0.7 \%$ sterols (Zlatanov and Ivanov, 1995) and 234.1-1550.9 mg/kg tocopherols (Ivanov and Aitzetmuller, 1995) in Apiaceae seed oils. Relatively high levels of tocopherols were determined in Mentha spicata $L$. seed oil, $649.7 \mathrm{mg} / \mathrm{kg}$.

The qualitative and quantitative phospholipid composition of the investigated oils is presented in Table II.

Table I

Content of glyceride oil in Lamiaceae seeds and phospholipids, sterols and tocopherols in the oils*

\begin{tabular}{l|c|c|c|c}
\hline \multicolumn{1}{c|}{ Botanical name } & $\begin{array}{c}\text { Content of oil } \\
\text { in seeds, } \\
\% \text { wt }\end{array}$ & $\begin{array}{c}\text { Content of } \\
\text { phospholipids } \\
\text { in oils, \% wt }\end{array}$ & $\begin{array}{c}\text { Content of } \\
\text { sterols in } \\
\text { oils, \% wt }\end{array}$ & $\begin{array}{c}\text { Content of } \\
\text { tocopherols in } \\
\text { oils, mg/kg }\end{array}$ \\
\hline 1. Leonurus cardiaca L. & 26.5 & 1.0 & 0.1 & 176.9 \\
\hline 2. Marrubium vulgare L. & 24.4 & 1.3 & 0.3 & 14.7 \\
\hline 3. Mentha spicata L. & 21.9 & 1.4 & 0.2 & 649.7 \\
\hline 4. Nepeta cataria L. & 15.7 & 1.6 & 0.1 & 6.3 \\
\hline 5. Salvia aethopis L. & 28.6 & 1.3 & 0.1 & 18.2 \\
\hline 6. Salvia nutans L. & 27.4 & 1.2 & 0.1 & 97.8 \\
\hline 7. Salvia verticalata L. & 21.7 & 1.3 & 0.1 & 63.7 \\
\hline
\end{tabular}

*Average of three determinations 
Table II

Phospholipid composition of Lamiaceae seed oils*

\begin{tabular}{lccccccccc}
\hline Botanical name & \multicolumn{1}{c}{ PC } & PE & PI & PA & LPC & LPE & MPG & DPG & Oth. \\
\hline 1. Leonurus cardiaca $L$. & 55.5 & 6.6 & 27.9 & 2.2 & 0.3 & 2.2 & 3.6 & 0.3 & 1.4 \\
2. Marrubium vulgare L. & 47.3 & 18.0 & 27.2 & 3.3 & 0.9 & 1.1 & 0.7 & 0.5 & 1.0 \\
3. Mentha spicata $L$. & 45.0 & 24.6 & 19.1 & 4.7 & 1.3 & 2.0 & 2.1 & 1.2 & - \\
4. Nepeta cataria L. & 46.5 & 9.8 & 30.2 & 6.1 & 1.6 & 1.6 & 4.0 & 0.2 & - \\
5. Salvia aethopis L. & 50.0 & 16.1 & 29.4 & 2.1 & - & 0.3 & 0.9 & 0.6 & 0.6 \\
6. Salvia nutans L. & 35.5 & 5.8 & 27.0 & 16.8 & 1.6 & 3.1 & 3.1 & 3.9 & 3.2 \\
7. Salvia verticalata $L$. & 45.9 & 21.6 & 22.6 & 3.7 & - & 2.6 & 0.7 & 2.9 & - \\
\hline
\end{tabular}

PC - Phosphatidylcholine, PE - Phosphatidylethanolamine, PI - Phosphatidylinositol, PA - Phophatidic acids, LPC -Lysophosphatidylcholine, LPE - Lysophosphatidylethanolamine, MPG - Monophosphatidylglycerol, DPG - Diphosphatidylglycerol, Oth. - Others.

* Average of three determinations

The obtained results show that the qualitative phospholipid composition is varied. All major classes were observed in the seeds. Phosphatidylcholine was the main component $(35.5-55.5 \%)$ in all phospholipid fractions, followed by phosphatidylinositol (19.1 $30.2 \%)$. In the four species of oils the content of phosphatidylcholine was found to be $50 \%$ above. It was significantly higher than in the other investigated oils, like Apiaceae (Ivanov et al, 1999) and Rosaceae family (Zlatanov et al, 1997) where 25.0 - $35.0 \%$ of phosphatidylcholine was established. On the other hand, the content of phosphatidylethanolamine (5.8 $24.6 \%$ ) was considerably lower in comparison with the quantity of above mentioned oils. In all phospholipid fractions were detected high percentages of phosphatidylinositol. The other phospholipids are presented in negligible quantities.

The content of the free and esterified sterols is given in Table III. The greatest part of them is in the free form (73.5 - 86.3\%). Individual sterol composition was presented in Table IV. $\beta$-sitosterol predominates in all sterol fractions, followed by campesterol. Brassicasterol

Table III

Ratio of free and esterified sterols in Lamiaceae glyceride oils*

\begin{tabular}{l|c|c}
\hline Botanical name & $\begin{array}{c}\text { Content of free sterols in } \\
\text { sterol fraction, \% wt }\end{array}$ & $\begin{array}{c}\text { Content of ester. sterols in } \\
\text { sterol fraction, \% wt }\end{array}$ \\
\hline 1. Leonurus cardiaca $L$. & 79.7 & 20.3 \\
\hline 2. Marrubium vulgare $L$. & 80.2 & 19.8 \\
\hline 3. Mentha spicata $L$. & 74.5 & 25.5 \\
\hline 4. Nepeta cataria $L$. & 73.5 & 26.5 \\
\hline 5. Salvia aethopis . & 68.6 & 31.4 \\
\hline 6. Salvia nutans L. & 64.8 & 35.2 \\
\hline 7. Salvia verticalata $L$. & 86.3 & 13.7 \\
\hline
\end{tabular}

${ }^{*}$ Average of three determinations 


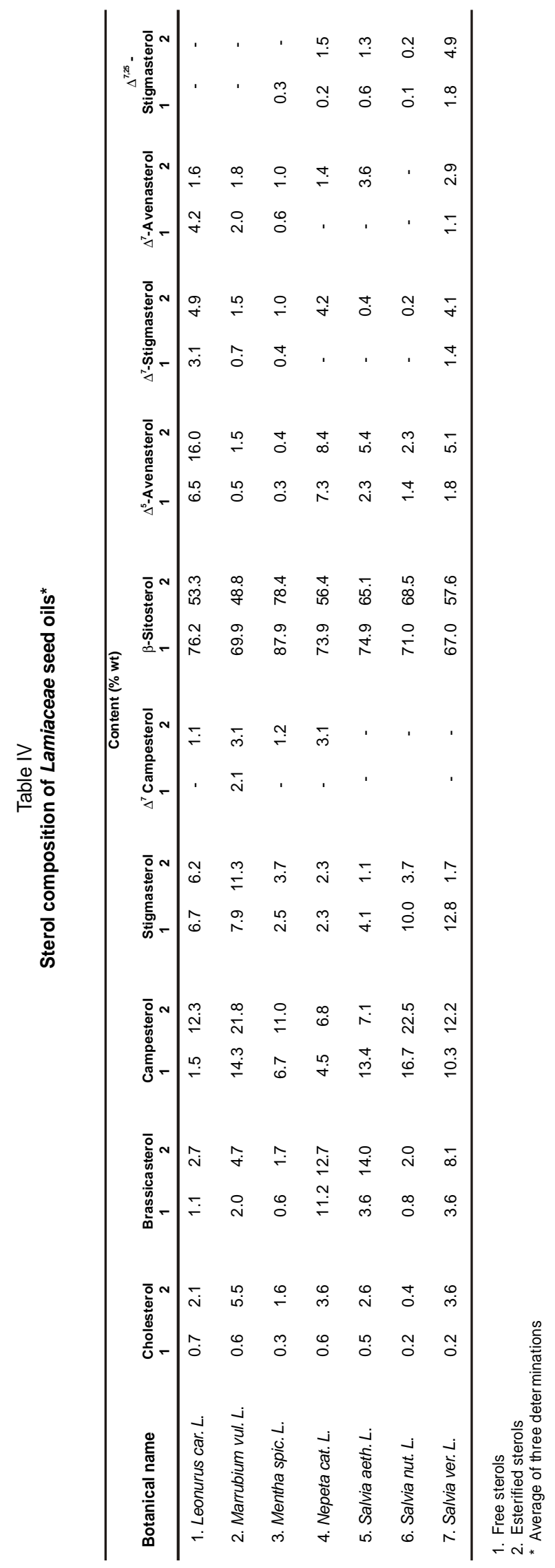


Table V

Tocopherol composition of Lamiaceae seed oils*

\begin{tabular}{|c|c|c|c|c|c|c|c|}
\hline \multirow{2}{*}{ Botanical name } & \multicolumn{7}{|c|}{ Content ( $\%$ wt) } \\
\hline & $\alpha$ & $\alpha-3$ & $\beta$ & $\gamma$ & $\gamma-3$ & $\delta$ & $\delta-3$ \\
\hline 1. Leonurus cardiaca $L$. & 5.1 & 8.7 & - & 13.5 & 1.5 & 70.5 & 0.7 \\
\hline 2. Marrubium vulgare $L$. & 48.5 & 9.4 & tr. & 35.9 & 6.2 & - & \\
\hline 3. Mentha spicata $L$. & 98.5 & - & - & - & - & 1.5 & - \\
\hline 4. Nepeta cataria $L$ & 68.0 & 11.8 & - & - & - & 20.2 & - \\
\hline 5.Salvia aethopis $L$. & 99.9 & 0.1 & - & - & - & - & - \\
\hline 6. Salvia nutans $L$. & 51.6 & - & 0.6 & 24.9 & 17.1 & 15.8 & - \\
\hline 7. Salvia verticalata $L$. & 57.8 & 1.3 & 1.1 & 39.8 & - & - & - \\
\hline
\end{tabular}

*Average of three determinations

was detected in significant amount in Nepeta cataria $L$. oil only $(11.2 \%$ in free form and $12.7 \%$ in sterol esters). High level of stigmasterol derivatives (11.3\%) was determined in esterified sterols of Marrubium vulgare $L$. and in free form in Salvia nutans $L$. and Salvia verticalata $L$. seed oils. High percentage of $\Delta^{5}$-avenasterol $(16.0 \%)$ was found in sterol esters of Leonurus cardiaca $L$. seed oil. A marked difference was detected between free and esterified sterols in the cholesterol content. In the fraction of sterol esters a significantly higher cholesterol percentage was observed ( $0.4-5.5 \%$ respectively) than in the free form (0.2 - $0.5 \%$ ). Similar results were reported earlier about glyceride oils of Apiaceae (Zlatanov M., 1994, Zlatanov M. et al, 1997) and for tomato seed oils (Kiosseoglou and Boskou, 1989, Tiscornia et al, 1976). The content of $\beta$-sitosterol in free form $(67.0-87.9 \%)$ is higher than in esterified form (48.8-74.4\%). Other sterol constituents were presented in insignificant quantities or in traces in all investigated oils.

Tocopherol and tocotrienol composition of the oils is shown in Table V. Tocopherols were found to be the major part in all the tocopherol and tocotrienol fractions: the ratio tocopherols: tocotrienols varies from 100: 0,1 to 88.2 : 11.8. $\alpha$-tocopherol is the predominant component in almost seed oils (48.5 - 99.5\%) followed by $\gamma$-tocopherol. Only in the Leonurus cardiaca $L$. oil $\delta$-tocopherol was found to be the main component (70.5\%). All other tocopherols and tocotrienols have been detected in negligible amounts.

\section{REFERENCES}

Beshkov M., L. Ivanova, 1972, Determination of phospholipids in lipid mixtures, Sci. Works of High Inst. Food and Flavour Ind., Plovdiv (Bulg.), 20, 3, 231-234.

Homberg E., B. Bielefeld, 1989, Sterinzusamensetzung und Steringehalt in 41 verschiedenen pflanzlichen und tierichen Fetten, Fat. Sci. Technol., 91,1, 23-27

Georgiev E., D. Dimitrov, M. Angelakova, 1989, A Guide of Parfumery and Cosmetic industry, Publ. Co. Technika, Sofia.
Gramatikov D., 1992, A guide for plants in Bulgaria, Publ. House of Bulgarian Academy of Sciences, Sofia.

Ivanov S., K. Aitzetmüller, 1995, Untersuchungen über die Tocopherol- und Tocotrienolzusammensetzung der Samenöle einiger Vertreter der Familie Apiaceae, Fat. Sci. Technol., 97, 1, 24-29.

Ivanov S., M. Zlatanov, E. Ivanova, K. Aitzetmüller, 1999, Phospholipid composition of 14 types glyceride oils from representatives of the fam. Apiaceae of the Bulgarian wild flora, Fett/Lipid, 101,8 307-309.

ISO, 1229, 1999, Animal and vegetable fats and oils. Determination of individual and total sterols contents. Gas chromatographic method.

ISO, 9936, 1997, Animal and vegetable fats and oils. Determination of Tocopherols and tocotrienols contents. Method using HPLC.

Kates M., Techniques of Lipidology,1972, American Elsevier Publ. Co.,New York.

Kiossseoglou B., D. Boskou, 1989, The composition of free and esterified sterols in tomato seed oil, Oleagineux, $44,2,113-115$.

Pamukov D. and Ch. Ahtardjiev, 1990, Natural Pharmacy, Publ. Co. Zemizdat, Sofia.

Slavik B. and V. Choe, 1978, Wild pflanzen, Publ. Co. Artia, Praha.

Stojanov N., B. Kitanov, Wild useful plants in Bulgaria, 1960, Publ. Co. of Bulg. Acad. of Science, Sofia.

Sokolov S. And I. Zamotaev, 1984, A Guide of pharmaceutical plants, Publ. Co. Meditsina, Moscow.

Tiscornia E., F.Camurat, P. Gastaldo and M. Pagano, 1976, La Frazione sterolica delle Olio di Pomodoro, Riv. Ital. Sost. Grasse , 53, 119-129.

Zlatanov M., S. Ivanov, 1995, Untersuchungen über die Sterinzusammensetzung der Glyceridöle einiger Vertreter der Familie Apiaceae, Fett Wissenschaft Technologie, 10, 381-383.

Zlatanov M., 1994 Untersuchungen uber die Phospholipidzusammensetzung der Glyceridole einiger Vertreter der Familie Apiaceae, Fett Wissenschaft Technologie, 96, N. $12,456-457$.

Zlatanov M., S. Ivanov, G. Antova, L. Kouleva, 1997, Study of phospholipid composition of Rosaceae seed oils, Riv. Ital. Sost. Grasse, v. LXXIV, settebre, 409-410 .

Weiss R., 1974, Lehrbuch der Phytoterapie, Stuttgart, Hippokrates Verlag.

Recibido: Octubre 2002 Aceptado: Agosto 2003 